\title{
Myeloid differentiation primary response protein 88 (MyD88)-deficient dendritic cells exhibit a skewed cytokine response to BCG
}

\author{
Pawan Kumar ${ }^{1,2}$ and Sangeeta Bhaskar ${ }^{2^{*}}$
}

\begin{abstract}
Objective: Macrophages and dendritic cells (DCs) play key role in the recognition of mycobacterial infection and mounting of antimycobacterial immunity. In case of macrophages, recognition of BCG and other mycobacteria has been attributed predominantly to MyD88-dependent singling. Interestingly, in previous study with bone marrowderived DCs, we have shown that BCG promotes the survival of wild-type and MyD88 ${ }^{-1}$ cells to the comparable levels. In the present study, we further examined MyD88 ${ }^{-/}$DC's response to BCG.

Results: Bone marrow-derived DCs from wild-type and MyD88 ${ }^{-1-}$ mice were stimulated with BCG and analyzed for cytokine secretion. As expected, BCG-stimulated wild-type DCs produced significant amount of TNF-a and IL-12p40 in response to $B C G$. Interestingly, BCG-stimulated MyD88 ${ }^{-1-}$ DCs were also found to secret significantly higher levels of TNF- $a$ and IL-12p40, compared with unstimulated DCs. We further observed that wild-type DCs produced significant level of immunosuppressive cytokine IL-10 in response to BCG, whereas MyD88 ${ }^{-/-}$DCs secreted very low amount of IL-10 when stimulated with BCG. These findings demonstrated that MyD88 ${ }^{-/-}$DCs exhibit a skewed cytokine response to $\mathrm{BCG}$.
\end{abstract}

Keywords: Dendritic cells, Cytokine secretion, Mycobacteria, MyD88, Tuberculosis, Immunity

\section{Introduction}

Dendritic cells and macrophages are the antigen presenting cells involved in the recognition of BCG and other mycobacteria, and activation of antimycobacterial immunity [1]. They possess an array of pattern recognition receptors (PRRs), specialized in the recognition of molecular patterns present in pathogenic microbes. Tolllike receptors (TLRs) are one of the most prominent and most characterized trans-membrane PRRs. TLR engagement by mycobacteria has been shown to affect diverse immunological outcomes, including cytokine secretion, antigen presentation, cell survival, and cellular differentiation $[1,2]$.

MyD88 is an adapter protein, relaying TLR engagement signals across the plasma membrane. Defects

\footnotetext{
*Correspondence: sangeeta@nii.ac.in

2 PDC-I, National Institute of Immunology, Aruna Asaf Ali Marg, New Delhi 110067, India

Full list of author information is available at the end of the article
}

in MyD88-dependent signalling have been shown to severely impair the innate immunity [3]. MyD88 deficiency in macrophages results in their hyporesponsiveness to BCG and other mycobacteria, characterized by diminished secretion of proinflammatory cytokines and inducible nitric oxide synthase (iNOS) $[4,5]$. However, the role of MyD88-dependent signaling in DC response to mycobacteria remains poorly understood. A study by Fremond et al. [6] has demonstrated drastic reduction in IL-12 and IL- $1 \beta$ secretion by BCG-stimulated MyD $88^{-/-}$ DCs, compared with wild-type DCs. On the other hand, heightened antimycobacterial $\mathrm{T}$ cell responses in

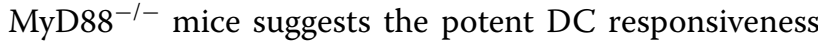
to the bacilli in these animals $[7,8]$.

In our previous study, we have shown that BCG promotes the survival of wild-type and MyD88 ${ }^{-1-}$ DCs to the comparable levels [9]. In the present manuscript, we further examined the role of MyD88 in DC activation by BCG. Bone marrow-derived DCs from wild-type and MyD88 ${ }^{-1-}$ mice were stimulated with BCG and analyzed 
for TNF- $\alpha$, IL-12p40 and IL-10 secretion by ELISA. It was observed that both wild-type and MyD88 ${ }^{-1-}$ DCs produced significant amounts of TNF- $\alpha$ and IL-12p40 in response to the bacilli. Further, we noticed that wildtype DCs, but not MyD88 ${ }^{-/-}$DCs secreted significant amount of IL-10 in response to BCG. These findings demonstrated a robust but skewed cytokine response of

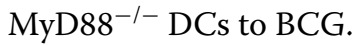

\section{Main text}

\section{Materials and methods}

Wild-type and MyD88 ${ }^{-1-}$ C57BL/6 mice of 6-8 weeks age were obtained from the animal house facility of the National Institute of Immunology, New Delhi. Mice were euthanized by $\mathrm{CO}_{2}$ asphyxiation method. DCs were derived from mouse bone-marrow cells by culturing them in the presence of GM-CSF (Peprotech Asia, Israel) as described previously [10]. Purity of dendritic cells, as determined on the basis of CD11c and MHCII expression by flow cytometry, was 90\%. BCG (strain Danish 1331, kindly provided by Prof. Anil Tyagi, University of Delhi South Campus, New Delhi, India) was cultured in $7 \mathrm{H} 9$ broth (BD Difco, India) supplemented with $10 \%$ albumin-dextrose-catalase (ADC) enrichment, $0.5 \%$ glycerol and $1 \%$ tween-80. Bacilli were cultured at $36{ }^{\circ} \mathrm{C}$ in static condition with intermittent manual shaking. DCs were plated in 24 -well cell culture plate $\left(1.5 \times 10^{6}\right.$ cells per well) and stimulated with BCG at the multiplicity of infection (MOI) of 10 as described previously [9]. Culture supernatants were collected after $24 \mathrm{~h}$ and analyzed for TNF- $\alpha$, IL-12p40 and IL-10 using ELISA kits as described by the manufacturer (BD Biosciences). Data were analyzed by one way ANOVA (with Tukey's comparison test applied post-analysis) using GraphPad Prism 5 software.

\section{Results}

Culture supernatants from BCG-stimulated wild-type and $\mathrm{MyD}^{-1-} \mathrm{DC}$ were analyzed for proinflammatory cytokines TNF- $\alpha$ and IL-12p40. As expected, wildtype DCs produced significant amounts of TNF- $\alpha$ and IL-12p40 in response to BCG, compared with unstimulated DCs (Fig. 1a, b). Interestingly, BCG-stimulated MyD88 ${ }^{-1-}$ DCs also produced significant levels of TNF- $\alpha$ and IL-12p40, compared with unstimulated MyD88 ${ }^{-1-}$ DCs. Levels of IL-12p40 secreted by BCG-stimulated wild-type and MyD88 ${ }^{-/-}$DCs were comparable, whereas TNF- $\alpha$ secretion by BCG-stimulated wild-type DCs was significantly higher, compared with that produced BCG-stimulated MyD88 ${ }^{-1-}$ DCs (Fig. 1a, b). We also examined IL-10 secretion by BCG-stimulated wild-type

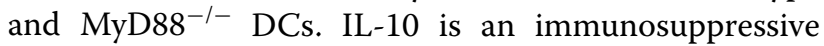
cytokine involved in controlling the collateral damage to

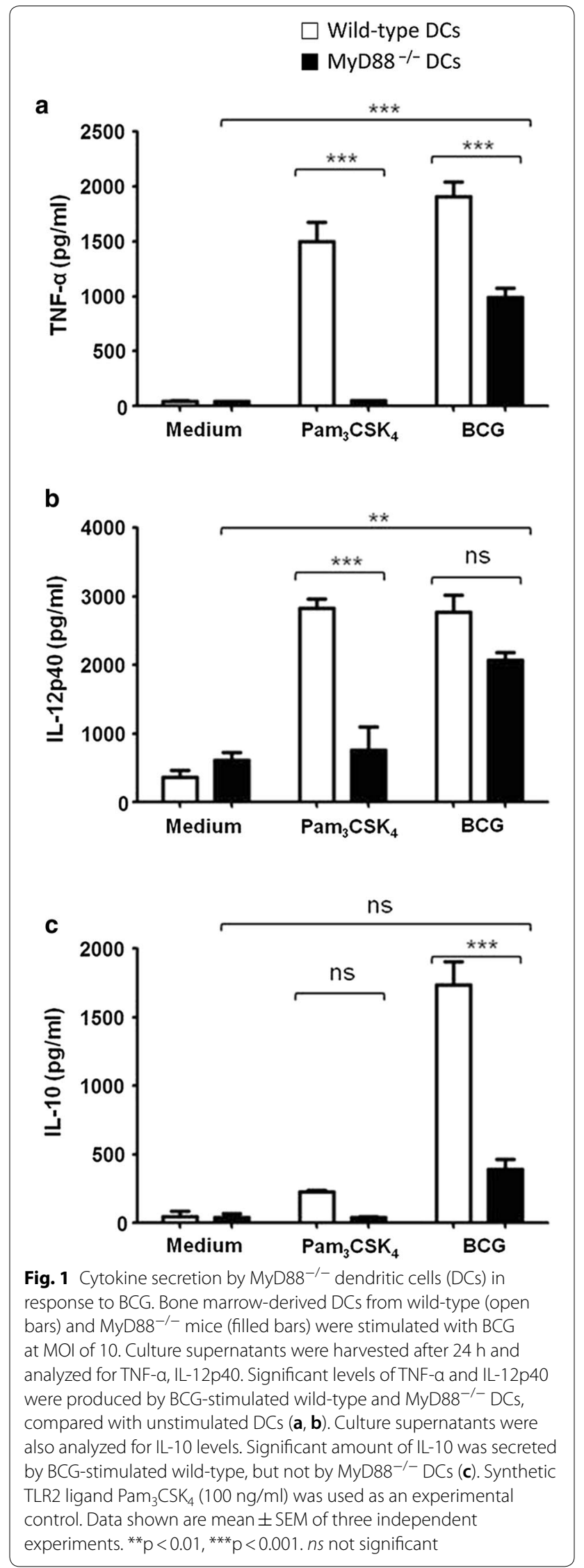


surrounding tissue during immune reaction [11]. It was observed that BCG-stimulated wild-type DCs produced significant amount of IL-10. However, MyD88 ${ }^{-1-}$ DCs failed to produce a significant level of IL-10 in response to BCG (Fig. 1c). Synthetic TLR2 ligand $\mathrm{Pam}_{3} \mathrm{CSK}_{4}$ was used as an experimental control.

\section{Discussion}

The present study was undertaken to gain insight into our previous observations, wherein BCG was found to promote survival in both wild-type and MyD88 ${ }^{-1-}$ DCs [9]. In keeping with these observations, the present study demonstrates the potent responsiveness of $\mathrm{MyD} 88^{-/-}$ DCs to BCG. Similar to wild-type DCs, MyD88 ${ }^{-1-}$ DCs produced significant levels of IL-12p40 and TNF- $\alpha$ in response to BCG. IL-12 promotes differentiation of naïve $T$ cells into $T_{H} 1$ cells and stimulates IFN-gamma production by $\mathrm{T}$ lymphocytes $[1,12]$. TNF- $\alpha$ is involved in macrophage activation, inflammation and other immunological phenomena $[1,12]$. In agreement with production of inflammatory cytokines by BCG-stimulated MyD88 $^{-1-}$ DCs, MyD88-deficient mice have been shown to mount strong $\mathrm{T}$ cell responses to mycobacterial infection [7].

DCs, being the key antigen presenting cells, exert control over $\mathrm{T}$ cell responses. Depending on the nature of antigen, DCs can induce normal or hyperactive $\mathrm{T}$ cell responses or can induce $\mathrm{T}$ cell anergy. Different outcomes of antigen presentation by DCs rely on delicate balance of proinflammatory (i.e. IL-12, IL-17, TNF- $\alpha$ ) and anti-inflammatory (i.e. IL-10, TGF- $\beta$ ) cytokines. Interestingly, our results showed that in contrast to wildtype DCs, which produced both pro- and anti-inflammatory cytokines, MyD88 $8^{-1-}$ DCs secreted drastically reduced level of IL-10 in response to BCG. IL-10 is an immunosuppressive cytokine (involved in the peripheral immune tolerance); IL-10-deficient mice have been shown to develop a variety of inflammatory and autoimmune conditions [11].

Skewed cytokine response of BCG-stimulated MyD88 ${ }^{-/-}$ DCs provides an important insight into aggravated immune response and high mortality in $M$. tuberculosis $(M t b)$-infected MyD88 ${ }^{-1-}$ mice $[7,8]$. In the absence of IL-10, predominant activity of proinflammatory cytokines drives the $\mathrm{T}$ cell response and inflammatory reaction to the pathologically intense levels, which could lead to lung tissue damage and death. What molecular mechanisms are involved in mycobacterial recognition by MyD88 ${ }^{-1-} \mathrm{DCs}$, however, remains a key question. DCs are known to express a large repertoire of PRRs and we are further examining different PRRs for their involvement in MyD88 ${ }^{-1-}$ DC activation by BCG. Taken together, our findings demonstrate the potent response of MyD88 ${ }^{-1-}$ DCs to BCG and suggest a putative mechanism for overly active antimycobacterial immune response in $M t b$-infected $\mathrm{MyD} 88^{-/-}$mice.

\section{Limitations}

DCs are heterogeneous cell population. Multiple DC subsets (e.g. lymphoid, myeloid, plasmacytoid, langerhans cells) with significant variations in their functions have been defined in mice and humans [13]. The present study has been carried out using bone marrow-derived DCs from wild-type and MyD88 ${ }^{-/-}$mice. Therefore, results presented in this manuscript are specifically valid for these cells.

\section{Abbreviations \\ DC: dendritic cell; PRRs: pattern recognition receptors; TLR: toll-like receptor; APC: antigen-presenting cells; BCG: bacillus Calmette-Guerin; Mtb: Mycobacte-} rium tuberculosis.

\section{Authors' contributions}

PK carried out the experiments. PK and SB planned the study, analyzed the data and prepared the manuscript. Both authors read and approved the final manuscript.

\section{Author details}

1 Present Address: Dept. of Preventive Oncology, Dr. B.R Ambedkar Institute Rotary Cancer Hospital, All India Institute of Medical Sciences, Ansari Nagar, New Delhi 110029, India. ${ }^{2}$ PDC-I, National Institute of Immunology, Aruna Asaf Ali Marg, New Delhi 110067, India.

\section{Acknowledgements}

The authors are thankful to Prof. Anil Tyagi, University of Delhi South Campus for kindly providing a stock of BCG.

Competing interests

The authors declare that they have no competing interests.

Availability of data and materials

Data is available upon reasonable request.

Consent for publication

Not applicable.

\section{Ethics approval and consent to participate}

This work was approved by the Institutional Animal Ethics Committee of the National Institute of Immunology, New Delhi (IAEC Approval No. 205/13).

\section{Funding}

This work was supported by core research grant from the National Institute of Immunology, New Delhi. The funding body did not play any role in designing of the study and collection, analysis, and interpretation of data and in writing the manuscript.

\section{Publisher's Note}

Springer Nature remains neutral with regard to jurisdictional claims in published maps and institutional affiliations.

Received: 29 November 2018 Accepted: 14 January 2019

Published online: 23 January 2019

\section{References}

1. O'Garra A, Redford PS, McNab FW, Bloom Cl, Wilkinson RJ, Berry MP. The immune response in tuberculosis. Annu Rev Immunol. 2013;31:475-527. 
2. Krutzik SR, Tan B, Li H, Ochoa MT, Liu PT, Sharfstein SE, Graeber TG, Sieling PA, Liu Y-J, Rea TH. TLR activation triggers the rapid differentiation of monocytes into macrophages and dendritic cells. Nat Med. 2005;1 1:653.

3. Deguine J, Barton GM. MyD88: a central player in innate immune signaling. F1000Prime Rep. 2014;6:97.

4. Kumar P, Tyagi R, Das G, Bhaskar S. Mycobacterium indicus pranii and Mycobacterium bovis BCG lead to differential macrophage activation in Toll-like receptor-dependent manner. Immunology. 2014;143:258-68.

5. Lim Y-J, Yi M-H, Choi J-A, Lee J, Han J-Y, Jo S-H, Oh S-M, Cho HJ, Kim DW Kang M-W. Roles of endoplasmic reticulum stress-mediated apoptosis in M1-polarized macrophages during mycobacterial infections. Sci Rep. 2016;6:37211.

6. Fremond CM, Togbe D, Doz E, Rose S, Vasseur V, Maillet I, Jacobs M, Ryffel B, Quesniaux VF. IL-1 receptor-mediated signal is an essential component of MyD88-dependent innate response to Mycobacterium tuberculosis infection. J Immunol. 2007:179:1178-89.

7. Fremond CM, Yeremeev V, Nicolle DM, Jacobs M, Quesniaux VF, Ryffel B. Fatal Mycobacterium tuberculosis infection despite adaptive immune response in the absence of MyD88. J Clin Invest. 2004;114:1790.
8. Sugawara I, Yamada H, Mizuno S, Takeda K, Akira S. Mycobacterial infection in MyD88-deficient mice. Microbiol Immunol. 2003;47:841-7.

9. Kumar P, John V, Gupta A, Bhaskar S. Enhanced survival of BCG-stimulated dendritic cells: involvement of anti-apoptotic proteins and NF-KB. Biol Open. 2018;1:1. https://doi.org/10.1242/bio.032045.

10. Kumar P, John V, Marathe S, Das G, Bhaskar S. Mycobacterium indicus pranii induces dendritic cell activation, survival, and Th1/Th17 polarization potential in a TLR-dependent manner. J Leukoc Biol. 2015;97:511-20.

11. O'Garra A, Vieira PL, Vieira P, Goldfeld AE. IL-10-producing and naturally occurring CD4+ Tregs: limiting collateral damage. J Clin Investig. 2004;114:1372-8.

12. O'Garra A, Britton WJ. Cytokines in tuberculosis. Handbook of tuberculosis. Weinheim: Wiley; 2008. p. 185-225.

13. Segura E. Review of mouse and human dendritic cell subsets. Methods Mol Biol. 2016;1423:3-15.
Ready to submit your research? Choose BMC and benefit from:

- fast, convenient online submission

- thorough peer review by experienced researchers in your field

- rapid publication on acceptance

- support for research data, including large and complex data types

- gold Open Access which fosters wider collaboration and increased citations

- maximum visibility for your research: over 100M website views per year

At BMC, research is always in progress.

Learn more biomedcentral.com/submissions 